\title{
ЗАСТОСУВАННЯ ОНТОЛОГІЧНИХ МОДЕЛЕЙ ЗНАНЬ ДЛЯ СВОЄЧАСНОЇ КОРЕКЦІЇ МЕДИЧНИХ СТАНДАРТІВ (НА ПРИКЛАДІ НАДАННЯ МЕДИЧНОЇ ДОПОМОГИ ХВОРИМ НА ЕКЗЕМУ)
}

\author{
В. В. Бойко, Н. В. Яременко \\ Національна медична академія післядипломної освіти імені П. Л. Шупика
}

\begin{abstract}
Представлено зіставлення даних літератури з «Протоколом надання медичної допомоги хворим на екзему». Інструментом зіставлення обрано онтологічні моделі, які на сьогодні стали популярною формою структурування знань.

Показано, що онтологія знань про екзему дозволяє структурувати відомості про надання медичної допомоги пацієнтам з даним захворюванням і рекомендувати ряд доповнень до існуючого «Протоколу надання медичної допомоги хворим на екзему». При побудові графологічних схем виявлені відмінності щодо етіопатогенезу, клінічних проявів, диференційної діагностики, а також діагностичної та лікувальної програм. Пропонується існуючий протокол доповнити більш новітніми даними, що відображені в сучасній літературі.
\end{abstract}

Ключові слова: екзема, протокол надання медичної допомоги хворим на екзему, онтологічні моделі знань.

\section{ПРИМЕНЕНИЕ ОНТОЛОГИЧЕСКИХ МОДЕЛЕЙ ЗНАНИЙ ДЛЯ СВОЕВРЕМЕННОЙ КОРРЕКЦИИ МЕДИЦИНСКИХ СТАНДАРТОВ (НА ПРИМЕРЕ ПРЕДОСТАВЛЕНИЯ МЕДИЦИНСКОЙ ПОМОЩИ БОЛЬНЫМ ЭКЗЕМОЙ)}

\author{
В. В. Бойко, Н. В. Яременко
}

Национальная медицинская академия последипломного образования имени П. Л. Шупика

\begin{abstract}
Представлены сопоставления данных литературы с «Протоколом оказания медицинской помощи больным экземой». Инструментом сопоставления выбраны онтологические модели, которые на сегодняшний день стали популярной формой структурирования знаний.

Показано, что онтология знаний о экземе позволяет структурировать сведения по оказанию медицинской помощи пациентам с данным заболеванием и рекомендовать ряд дополнений к существующему «Протоколу оказания медицинской помощи больным экземой». При построении графологических схем выявлены различия относительно этиопатогенеза, клинических проявлений, дифференциальной диагностики, а также диагностической и лечебной программ. Предлагается существующий протокол дополнить более новыми данными, которые отображены в современной литературе.
\end{abstract}

Ключевые слова: экзема, протокол оказания медицинской помощи больным экземой, онтологические модели знаний.

\section{APPLICATION OF ONTOLOGICAL MODELS OF KNOWLEDGE FOR TIMELY CORRECTION OF MEDICAL STANDARDS (FOR EXAMPLE PROVIDING MEDICAL CARE TO PATIENTS WITH ECZEMA)}

\section{P. L. Shupyk National Medical Academy of Postgraduate Education}

\begin{abstract}
The presented data comparing the literature on «Protocol of care for patients with eczema». The instrument chosen comparison ontological model that today have become a popular form of structuring knowledge.

It is shown that ontology knowledge on eczema allows structured data to provide medical care for patients of this disease and recommend a number of additions to the existing «Protocol of care for patients with eczema». When building a graphology scheme identified differences in pathogenesis, clinical manifestations, differential diagnosis and the diagnostic and therapeutic applications. It is proposed to supplement the existing protocol over the latest data reflected in contemporary literature.
\end{abstract}

Key words: eczema, protocol of care for patients with eczema, ontological model of knowledge.

(c) В. В. Бойко, Н. В. Яременко 
Вступ. Актуальним є завдання формування концептуальних «прозорих» представлень для слабоструктурованих предметних областей. Сьогодні провідною парадигмою структурування інформаційних потоків є онтології, або ієрархічні концептуальні структури, що формуються аналітиком на основі вивчення та структурування потоків інформації, документів, протоколів виявлення знань та інших джерел.

У процесі створення сучасних інтелектуальних інформаційних систем найчастіше потрібна інтеграція знань із різнорідних джерел і, як наслідок, ефективне вирішення завдань, пов'язаних iз їх тиражуванням. Тому і до цього дня актуальні дослідження, спрямовані на розроблення такого підходу до надання та тиражування знань, який, 3 одного боку, дозволяв би найадекватніше враховувати специфіку проблемної області, а 3 іншого - представляти та використовувати знання в деякому уніфікованому вигляді [1].

Мета роботи - формування стратегії подальшого вдосконалення надання медичної допомоги хворим на екзему.

Матеріали та методи. Використовували розроблену на кафедрі медичної інформатики НМАПО імені П. Л. Шупика багаторівневу систему

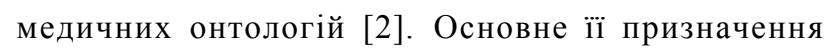
- забезпечення статистичного моделювання патологічного процесу будь-якої нозології.

Онтологічні моделі за час досліджень в цій області зазнали значного розвитку. На сьогодні для створення і підтримки онтологій існує цілий ряд інструментів, які, крім загальних функцій редагування та перегляду, виконують підтримку документування онтологій, імпорт і експорт онтологій різних форматів і мов, підтримку графічного редагування, керування бібліотеками онтологій тощо [2].

Будь-яка інформація може бути представлена у вигляді графових структур (наприклад, подання інформації у вигляді семантичних мереж), а тому перетворення інформації може розглядатися як перетворення графових структур. Графові структури даних є природним і наочним засобом представлення складних структур і процесів. Це дозволяє широко використовувати їх у комп'ютерних системах при вирішенні різних завдань. У багатьох 3 цих завдань графи використовуються для представлення даних неоднорідної структури. До таких завдань відносяться: уявлення дерев абстрактного синтаксису програм в трансляторах мов програмування, опис структури та обробки об'єктних моделей документів, обробка складних структур даних предметної області в прикладних завданнях тощо.

Більшість моделей, над якими проводяться перетворення, подаються у вигляді графоаналітичних структур. Перетворення описуються в термінах графів і операцій над ними і грунтуються на правилах, в результаті виконання яких породжується новий граф на основі заданого початкового [3].

Результати та їх обговорення. Поява «Протоколу надання медичної допомоги хворим на екзему» (наказ МО3 України від 08.05.2009 № 312 [4]) зіграла важливу роль у вдосконаленні надання медичної допомоги хворим 3 цією патологією. Проте подальше вивчення екземи $є$ абсолютно необхідним. Суттєву допомогу в цьому процесі можуть надати сучасні підходи до структуризації знань. При побудові графологічних схем виявлено відмінності між «Протоколом надання медичної допомоги хворим на екзему» та проаналізованою нами літературою щодо етіопатогенезу, клінічних проявів, диференційної діагностики, а також діагностичної та лікувальної програм.

У той же час, з'являється багато оновленої інформації щодо етіопатогенезу, яка, на жаль, не висвітлена в протоколі. Навколо цих даних виникає ряд дискусій, які залишаються невирішеними.

Так, обговорюється мультифакторна природа захворювання; участь нейрогенних механізмів, а саме дисбаланс вегетативної нервової системи 3 посилюючим тонусом парасимпатичного відділу, зміни біоелекричної активності головного мозку, зміни корково-підкоркової нейродинаміки, розвиток хронічного стрес-синдрому; алергійні реакції, які, без сумніву, пов'язані зі змінами концентрації в клітинах-ефекторів вторинних месенджерів типу цАМФ і цГМФ та змінами клітинних мембран, що провокують активацію перекисного окиснення ліпідів та зниження антиоксидантного захисту; імунологічні порушення, у тому числі асоційовані $з$ деякими антигенами системи HLA-B22, B27, $\mathrm{Cw} 1$, підвищення рівня $\operatorname{IgE}, \operatorname{IgG}$ та зниження $\operatorname{IgA}$, IgM; активація вогнищ хронічної інфекції; підвищення рівня глюкозаміногліканів та фібронектину; формування застійних та спастичних синдромів та підвищення активності тромбоцитогенезу [5-8].

Не менш важливу роль у виникненні екземи відіграють захворювання і функціональні порушення внутрішніх органів, особливо захворювання травного тракту, холецистити, ентероколіти, ентерити, 
синдром порушеного мембранного травлення, зниження ферментативної системи печінки, ендокринні порушення тощо [9-12].

Серед екзогенних факторів найбільше значення надається подразнювальним хімічним речовинам і агентам, смолам, мийним засобам, деяким металам (хром, нікель, кадмій) [13].

Оскільки клінічні прояви екзем різноманітні, то бажано внести до протоколу деякі критерії їх клінічної картини, які, на жаль, відсутні. Це, на наш погляд, сприяло б більш стандартизованому та прозорому опису клінічної картини та полегшувало роботу практикуючих лікарів.

Диференційна діагностика також є різноманітною, потребує більш детального вивчення та внесення їі до протоколу з метою вдосконалення останнього.

При аналізі діагностичної програми виявлено успішне використання алергопроб, культуральних методів (визначення числа колонієутворюючих одиниць (КУО), визначення показника мікробного обсіменіння шкіри (КУО / чашка)), гістопатології (при необхідності) та методу ІФА [14]. Застосовують також трансрезонансну функціональну топографію [15].

При дослідженні лікування знайдені статті, які описують позитивний вплив серамілу, що належать до групи імуномодуляторів із антибактеріальною активністю та супіроцину-В, що є комбінацією мупіроцину та високоефективного топічного

\section{Література}

1. Онтології і подання знань [Електронний ресурс]. Режим доступу: http://www.znannya.org/?view=ontologygive-knowledge.

2. Денисенко С. В. Використання принципів медичної онтології для побудови сценарних моделей післядипломного навчання лікарів і провізорів / С. В. Денисенко, О. П. Мінцер, О. С. Стрижак // Медична інформатика та інженерія. - 2013. - № 2. - С. 18-23.

3. Тимченко В. А. Система преобразования информации на основе проекций графовых структур / В. А. Тимченко, М. А. Князева // Information Technologies and Knowledge. - 2009. - Т. 3, № 1. - С. 37-55.

4. Протокол надання медичної допомоги хворим на екзему : наказ MO3 України від 08.05.2009 за № 312 (додаток № 21) [Електронний ресурс]. - Режим доступу: http:// www.moz.gov.ua/ua/portal/dn_20090508_312.html.

5. Бардова Е. А. Экзема в практике семейного врача: клинические формы, дифференциальный диагноз, лечение / Е. А. Бардова // Клиническая иммунология. Аллергология. Инфектология. - 2013. - № 1. - С. 22-27. кортикостероїда бетаметазону дипропіонату, а також транквілізатора афобазолу [16, 17, 18]. 3 інструментальних методів лікування успішно використовують озонотерапію і голкофлексотерапію та низькоінтенсивне електромагнітне випромінювання дециметрового діапазону [19, 20].

Отже, виникає необхідність зміни діючого протоколу та доповнення його оновленими даними сучасної літератури щодо етіопатогенезу, клінічних проявів, диференційної діагностики, а також діагностичної та лікувальної програм. Пропонується перегляд та внесення змін до діючого протоколу, для підвищення якості профілактичних та лікувально-діагностичних заходів, вирішення завдань збереження й підвищення здоров'я населення, що полягає у вдосконаленні стандартизації охорони здоров'я. Вважаємо, що подібну процедуру слід здійснювати 3 затвердженим у стандарті періодом.

Висновки. 1. Використано методику створення графологічної структури для систематизації інформації стосовно екземи. Онтологія знань із екземи дозволяє структурувати відомості щодо етіопатогенезу, клінічних проявів, диференційної діагностики, а також діагностичної та лікувальної програм.

2. Онтологічні уявлення знань 3 екземи дозволяють рекомендувати ряд доповнень до існуючого «Протоколу надання медичної допомоги хворим на екзему».

6. Денисова Я. Е. Современные представления о молекулярно-генетических механизмах возникновения истинной экземы / Я. Е. Денисова // Научные ведомости БелГУ Сер. Медицина. Фармация. - 2013. - № 18 (161), Вып. 23. - С. 5-11.

7. Иммунологическая концепция развития микробной экземы / Н. А. Абдрахимова, Г. Р. Мустафина, 3. Р. Хисматуллина [и др.] // Медицинский вестник Башкортостана. - 2014. - Т. 9, № 1. - С. 109-118.

8. Дерматология Фицпатрика в клинической практике / К. Вольф, Л. А. Голдсмит, С. И. Кац [и др.] ; пер. с англ. А. А. Кубанова. - М. : БИНОМ, 2012. - Т. 1. - 870 с.

9. Кубанова А. А. Дерматовенерология : клинические рекомендации / под ред. А. А. Кубановой. - М., 2006. - 298 c.

10. Мавров И. И. Основы диагностики и лечения в дерматологии и венерологии / И. И. Мавров, Л. А. Болотная, И. М. Сербина. - Х. : Факт, 2007. - 792 с.

11. Дерматовенерология. Национальное руководство. Краткое издание / под ред. Ю. С. Бутова, Ю. К. Скрип- 
кина, О. Л. Иванова. - М. : ГЭОТАР-Медиа, 2013. $896 \mathrm{c}$.

12. Mascara Ballester J. M. Pautas de diagnostico y terapeutica en dermatolog^a / J. M. Mascaro Ballester. Universidad de Barcelona, 2007. - Vol. 1. - 96 p.

13. Романенко И. М. Лечение кожных и венерических болезней : руководство для врачей / И. М. Романенко, В. В. Кулага, С. Л. Афонин. - М. : ООО Мед. информ. агенство, 2006. - Т. 2. - 886 с.

14. Никонова И. В. Состояние биоценоза кожи при микробной экземе / И. В. Никонова, Е. В. Орлов, П. Е. Коннов // Практическая медицина. - 2011. - № 2 (49). - C. 80-83.

15. Каракаева А. В. Диагностика поражения кожи при экземе с использованием трансрезонансной функциональной топографии / А. В. Каракаева, С. Р. Утц // Практическая медицина. - 2014. - № 8 (84). - С. 61-65.

16. Дедкова А. В. Антимикробная активность серамила (синтетического миелопептида) при терапии больных инфекционной экземой / А. В. Дедкова,
Л. А. Юсупова // Практическая медицина. - 2011. - № 4 (52). - С. 49-152.

17. О топической терапии больных микробной экземой / А. Л. Бакулев, С. С. Кравченя, Н. Н. Мурашкин [и др.] // Саратовский научно-медицинский журнал. - 2012. T. 8, № 2. - С. 596-600.

18. Тимофеева А. Н. Клиническая эффективность комплексной терапии хронической экземы с применением афобазола / А. Н. Тимофеева, И. И. Бобынцев, Л. В. Силина // Человек и его здоровье. - 2010. - № 2. - C. 38-141.

19. Базаев В. Т. Применение озона в комплексной терапии больных дисгидротической экземой, осложненной вторичной инфекцией / В. Т. Базаев, И. А. Качмазова, 3. Ю. Тезиева // Фундаментальные исследования. - 2014. - № 10. - С. 24-27.

20. Каракаева А. В. Низкоинтенсивное электромагнитное излучение дециметрового диапазона в лечении экземы / А. В. Каракаева, С. Р. Утц // Саратовский научномедицинский журнал. - 2014. - № 10 (3). - С. 546-551. 